\title{
Generalized Morphea
}

National Cancer Institute

\section{Source}

National Cancer Institute. Generalized Morphea. NCI Thesaurus. Code C116782.

A type of morphea characterized by four or more plaques found in two or more

anatomic locations. The plaques are indurated, generally well-delineated, and may include muscle atrophy in affected areas; there is no visceral involvement. 